\title{
EFFECTIVENESS OF FLEXIBLE ENDOSCOPY IN THE MANAGEMENT OF UPPER GASTROINTESTINAL TRACT FOREIGN BODIES AT A TERTIARY HOSPITAL OF WESTERN NEPAL
}

\author{
Shatdal Chaudhary,*, Prabin Khatri ${ }^{1}$, Suresh Shrestha ${ }^{2}$ \\ ${ }^{1}$ Department of Internal Medicine, Universal College of Medical Sciences, Bhairahawa, Nepal. \\ ${ }^{2}$ Departent of Internal Medicine, Chitwan Medical College, Bharatpur, Nepal.
}

Received: 6 Nov, 2019
Accepted: 7 Mar, 2020
Published: 13 Mar, 2020
Key words: Dysphagia; Endoscopy; Foreign body.
*Correspondence to: Shatdal Chaudhary, Universal
College of Medical Sciences, Ranigaon, Bhairahawa,
\[ \text { Nepal. } \]
Email: shatdalchaudhary@yahoo.com
DOI:https://doi.org/ 10.3126/jcmc.v10i1.28060
Citation
Chaudhary S, Khatri P, Shrestha S. Effectiveness of
flexible endoscopy in the management of upper
gastrointestinal tract foreign bodies at a tertiary
hospital of western Nepal.Journal of Chitwan Med-
ical College.2020;10(31):3-7.

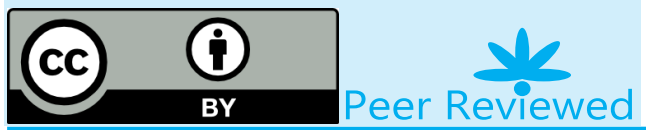

\section{INTRODUCTION}

Foreign body (FB) ingestion is one of the most challenging clinical situations faced by gastrointestinal (GI) endoscopists.In the United States, approximately 1,500 people die annually due to FB ingestion. ${ }^{1}$ It can occur in patients of any age group but is more commonly encountered in children which may account to $80 \%$ of cases. In majority of patients (80-90\%), the FB may pass through the gastrointestinal tract naturally. A noninvasive intervention is necessary in $10-20 \%$ of cases, and surgery may require in approximately $1 \%$ or less. ${ }^{2-4}$

The commonly ingested FBs in children are coins, toys, and batteries, ${ }^{5,6}$ whereas impaction of either bone or meat bolus while eating is common in adults. ${ }^{7}$ Ingested FBs can frequently lodge in the oesophagus. However, once it reaches in the stomach, it easily passes through the intestinal tract without any difficulty. If the objects are long, hard and sharp, like pins or fish bones, the risk of perforation of the gastrointestinal wall is high. ${ }^{8}$

Flexible endoscopy is the ideal choice for both diagnostic and therapeutic purposes in the management of upper gastrointestinal tract FBs. ${ }^{9}$ However, plain chest radiography abdominal ultrasonography or computed tomography (CT) scan can be done. ${ }^{9}$ Endoscopy has a success rate of greater than $95 \%$ with complication rates between $0-5 \% .^{1,10,11}$ Therefore, the present study was done to study the clinical profile of patients presenting with FB in the upper GI tract and to look for the effectiveness of endoscopy as a therapeutic tool in its management.

\section{METHODS}

It was a descriptive cross-sectional study carried out in the endoscopy unit of Universal College of Medical Sciences, Bhairahawa, Nepal from 1 January 2015 to 31 December 2018. The study was approved by the institutional review board of the institute. All the patients who underwent endoscopy with suspicion of ingestion of FB or features suggestive of an impacted $F B$ in the upper gastrointestinal tract were enrolled in this study. Those patients who refused to give consent or were endoscopy could not be completed were excluded from the study. Written informed consent was taken from all patients. After enrolment in the study, as per predesigned pro-forma, detailed history including age, sex, ethnicity, occupation, presenting complaints, history of dysphagia, abdominal pain, hematemesis or melena, smoking, alcohol ingestion and any co-morbid illness were taken. Detailed general physical and systemic examinations were performed. Appropriate investi- 
gations such as chest X-ray, ultrasonography of abdomen and computed tomography were done, if required. The upper gastrointestinal endoscopy was done in all cases on the same day of presentation if they presented during working hours or the next immediate working day with the intention to establish the diagnosis and to provide necessary therapeutic intervention to remove FB with appropriate endoscopic accessory tools. Fujinon video endoscope (EG-250WR5) was used for the endoscopy. The endoscopy was performed under $10 \%$ lignocaine spray by an experienced endoscopist. Endoscopic accessories like foreign body forceps, Roth net, tripod forceps, snare loop and endoscopy over-tube were used where required. Biopsy was taken from suspicious lesions where necessary. Clinical features of the foreign bodies, such as type, size, sharpness of edges, number, and location, were noted. All the data was entered in Microsoft excel sheet. Endoscopic data were analyzed

Table 1: Baseline characteristics of patients with foreign bodies including duration of foreign body impaction, endoscopic device, days of hospitalization and complication rate. Descriptive analysis was done as mean, percentage and standard deviation.

\section{RESULTS}

Total 64 patients with history of ingestion of FB or features suggestive of an impacted FB in the upper gastrointestinal tract underwent endoscopy and were enrolled in this study. Baseline characteristics and the demographic profile of the study subjects are depicted in table 1 . Mean age of patients in the present study was $34.78 \pm 21.84$ years. Patients less than 20 years of age constituted $40.63 \%(n=26)$ of the total study population. Females were more predominant than males in the present study (Table 1).

\begin{tabular}{|l|c|}
\hline Characteristics & $\mathbf{n}(\%)$ \\
\hline Age (yrs) & $26(40.63)$ \\
\hline$\leq 20$ & $9(14.1)$ \\
\hline $21-40$ & $20(31.3)$ \\
\hline $41-60$ & $9(14.1)$ \\
\hline$>60$ & $27(42.19 \%)$ \\
\hline Sex & $37(57.81 \%)$ \\
\hline Male & \\
\hline Female & $36(56.25 \%)$ \\
\hline Demographic data & $10(15.63 \%)$ \\
\hline Rupandehi & $6(9.37 \%)$ \\
\hline Kapilvastu & $4(6.25 \%)$ \\
\hline Nawalparasi west & $4(6.25 \%)$ \\
\hline Arghakhachi & $3(4.69 \%$ \\
\hline Dang & $1(1.56 \%)$ \\
\hline Palpa & \\
\hline Pyuthan & \\
\hline
\end{tabular}

Patients included in the present study were from 7 nearby districts from the study site. Rupandehi, Kapilvastu and Nawalparasi west were the three most common districts respectively which constituted $81.25 \%$ of the total study population (Table 1).

Accidental ingestion of foreign bodies was documented in all the study population. $42.19 \%(n=27)$ patients visited the ENT OPD of the hospital followed by emergency $(n=16,25 \%)$, medicine OPD ( $n=11,17.19 \%)$ and paediatric OPD $(n=10,15.62 \%)$ respectively.

Retrosternal discomfort with dysphagia ( $n=44,68.75 \%$ ) was the common symptom which led them to visit the hospital whereas rest of them were asymptomatic $(n=20,31.25 \%)$. In the present study $51.56 \%(n=33)$ patients presented within 24 hours, $25 \%(n=16)$ on $2^{\text {nd }}$ day, $9.38 \%(n=6)$ on $3^{\text {rd }}$ day, $4.69 \%$ $(n=3)$ on $4^{\text {th }}$ day and $9.38 \%(n=6)$ on $6^{\text {th }}$ day after ingestion.

Common sites for FB impaction was the lower oesophagus ( $n=34,53.13 \%)$ followed by stomach $(n=17,26.56 \%)$, upper oesophagus ( $n=10,15.62 \%)$ and pyriform fossa in $(n=3,4.69 \%)$ respectively. There were wide varieties of foreign bodies detected in upper gastrointestinal tract. Thirty-five (54.69\%) foreign bodies were related to edible products whereas 31 (45.31\%) foreign bodies were related to inedible products. The most common type of foreign object was an animal bone (17patients; $26.56 \%$ ), followed by meat ball (10 patients; $15.63 \%$ ), coin (9 patients; $14.06 \%$ ), denture (8 patients; $12.5 \%$ ), battery (4 patients; $6.25 \%$ ), plastic toy (4 patients; $6.25 \%$ ), mango seed 
(3 patients; $4.69 \%$ ) and fish bone (3 patients; $4.69 \%$ ). Other materials retrieved were wedding ring, safety pin, fennel seed,

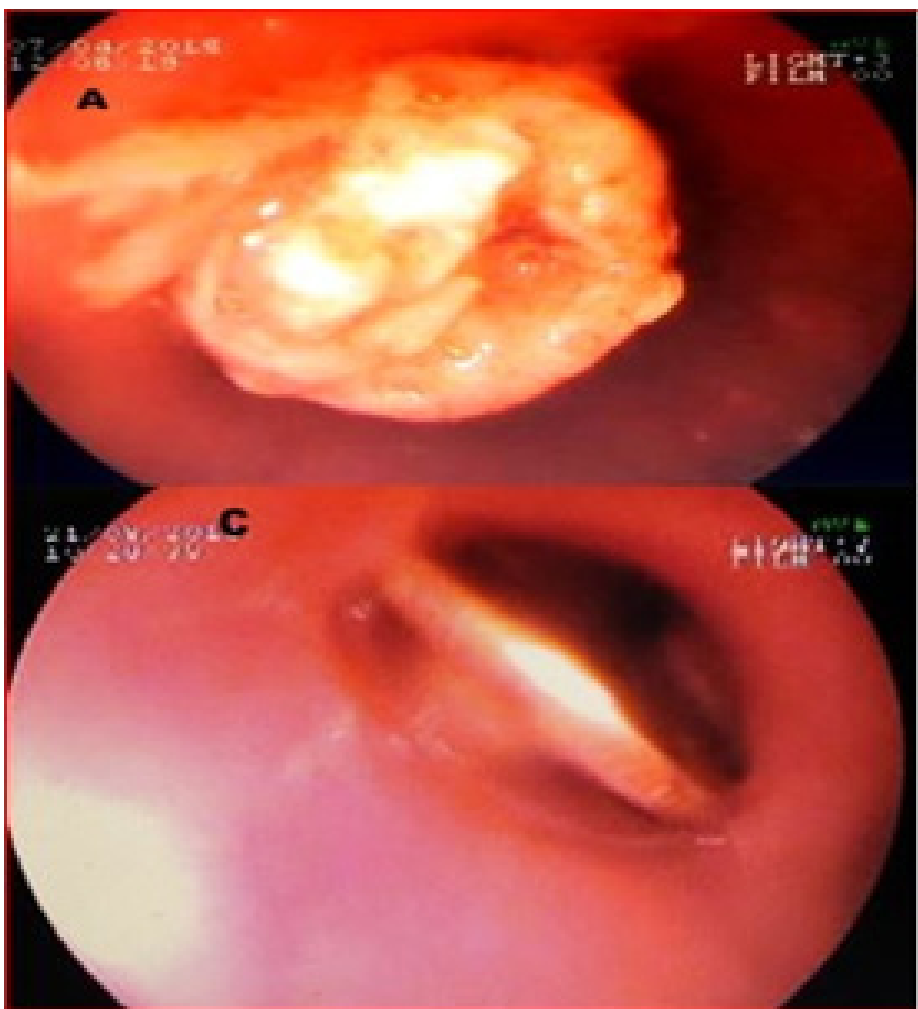

coat button and a sweet candy. (Table 2, Figure 1).

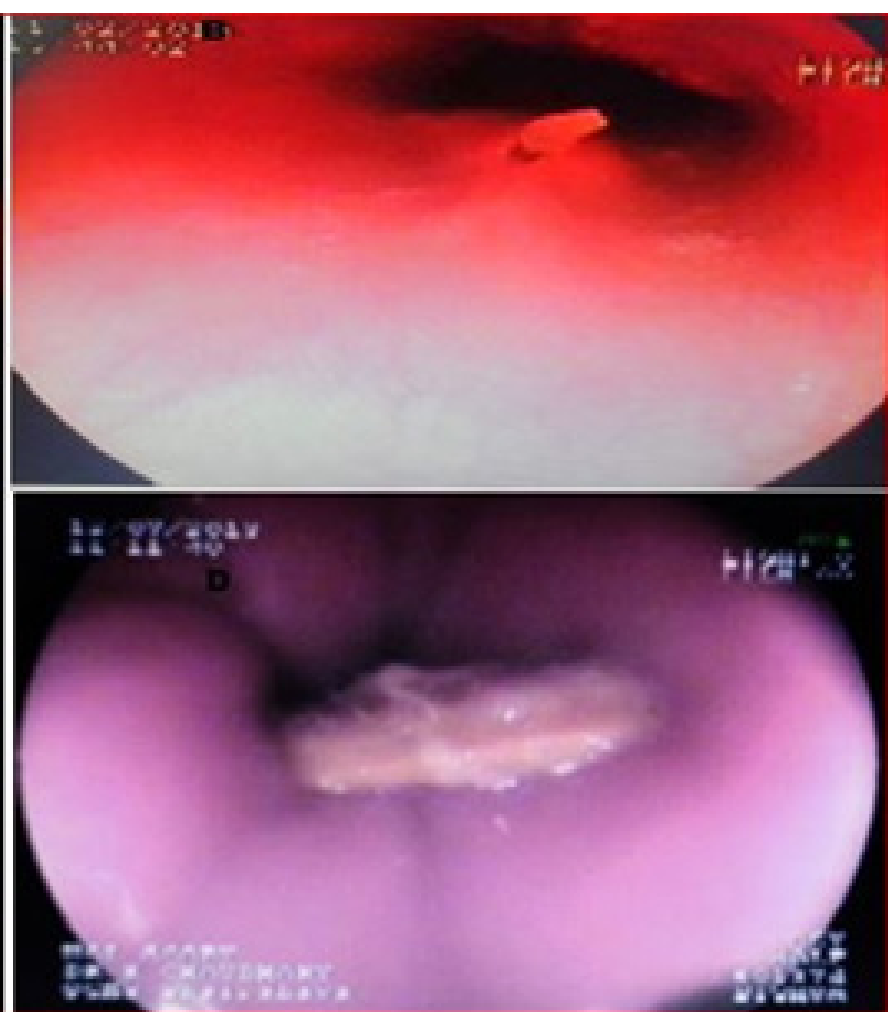

Figure 1: Foreign body in esophagus (A Meat ball, B Fish bone, C Coin, D Mango seed)

Table 2: Types of foreign bodies in patients

\begin{tabular}{|l|c|}
\hline Foreign bodies & $\mathbf{n}(\%)$ \\
\hline Animal bone & $17(26.56)$ \\
\hline Meat ball & $10(15.63)$ \\
\hline Coin & $9(14.06)$ \\
\hline Denture & $8(12.50)$ \\
\hline Battery & $4(6.25)$ \\
\hline Plastic toy & $4(6.25)$ \\
\hline Mango seed & $3(4.69)$ \\
\hline Fish bone & $3(4.69)$ \\
\hline Wedding ring & $2(3.13)$ \\
\hline Safety pin & $1(1.56)$ \\
\hline Fennel seed & $1(1.56)$ \\
\hline Coat Button & $1(1.56)$ \\
\hline Sweet candy & $1(1.56)$ \\
\hline Total & $64(100)$ \\
\hline
\end{tabular}

FB management was successful in 59 (92.19\%) patients with flexible endoscopy and failed in 5 (7.81\%) patients. Those cases where failure of endoscopic removal was seen had impacted large meat bolus with bone. All these cases underwent alternative procedures. Four (6.25\%) patients required rigid esophagoscopy and one patient required surgical management (laparotomy).

The preferred accessory devices used to extract a foreign body varied according to the type and location of the foreign bodies. For retrieval, commonly used accessory devices were rat tooth/ alligator foreign body forceps ( $n=35,54.69 \%$ ), snare loop $(n=15,23.44 \%)$, net $(n=11,17.19 \%)$, tripod forceps $(n=6$, 9.38\%) and biopsy forceps ( $n=1,1.56 \%)$. Overtube was used in $16(25 \%)$ patients. Foreign body push into the stomach was performed in 11 (17.19\%) cases. There were no complications related to the procedure. There were esophageal mucosal erosions in $8(12.50 \%)$ patients at the site of impaction, esophageal ulceration in $4(6.25 \%)$ patients and esophageal perforation in $2(3.13 \%)$ patients.

\section{DISCUSSION}

FB ingestion can be defined as materials swallowed accidentally or intentionally, or objects swallowed naturally when taking medication or food. In adults, most foreign body ingestion occurs accidentally, but may be a result of contributory factors, such as psychiatric disorders, mental retardation, alcohol consumption, esophageal motility disorder, esophageal stricture and an edentulous state.${ }^{12}$ In the present study all the patients had accidental ingestion of foreign body. Diagnosis of upper gastrointestinal foreign body is often clear with patient's history of foreign body ingestion. Patients may report a sudden onset of dysphagia while eating, often associated with chest pain or odynophagia and an inability to swallow oral secretions. In the present study all the patients had the history of ingestion of a foreign body. Sometimes patients may not 
able to provide a clear history so in these conditions a sudden refusal to eat, drooling of saliva, or respiratory symptoms such as coughing or wheezing due to aspiration should alert the physician to suspect foreign body ingestion. In another study from Taiwan the most frequent symptomatic complaint after foreign bodies ingestion was odynophagia $36.5 \%$ followed by dysphagia $27 \%$, foreign body sensation $27 \%$, chest pain $4.2 \%$, nausea $3.1 \%$, and others $2.2 \%$. Thirty-four patients (17.2\%) were asymptomatic. ${ }^{13}$

A careful physical examination should be done to look for features of esophageal or gastrointestinal perforation such as subcutaneous emphysema or peritonitis. Presence of drooling of saliva often suggests complete esophageal obstruction. Plain radiography of neck, chest of abdomen may show the foreign body especially containing metals or bone. Patient with perforation may have subcutaneous emphysema, pneumomediastinum, or pleural effusion. Barium studies are now obsolete due to easy availability of endoscopy and computerized tomography (CT) scan. ${ }^{14} \mathrm{CT}$ scanning is better to plain radiography in identifying the foreignbodies. ${ }^{15}$

Mean age of our patients was 34.78years ranging from minimum 8 years to maximum 70 years. Results are similar to another study where the mean age at the time of ingestion was 26.4 years (range 14 - 71 years). ${ }^{16}$ Another study from Pakistan shows that FB ingestion occurs mostly in the younger age group. ${ }^{17}$ In our study $\mathrm{FB}$ ingestion was more common in male then female. Male predominance was noted in many other studies. ${ }^{13,17}$ Potential sites for blocking for an ingested FB include the cricopharyngeus muscle or upper sphincter, aortic arch, left main stem bronchus, gastroesophageal junction or lower sphincter, pylorus, duodenal sweep, ileocecal valve, and anus. In the present study common sites for FB impaction was the lower esophagus $53.13 \%$ followed by stomach $26.56 \%$, upper esophagus $15.62 \%$ and pyriform fossa in $4.69 \%$ respectively. Which means esophagus was the most common site of lodgment site of ingested foreign bodies. This finding is similar to the another study where esophageal lodgment was seen in $75.6 \%$ of Incidents followed by the stomach $12.5 \%$, the pharynx $8.3 \%$, anastomoses $2.4 \%$, and the duodenum $1.2 \%$, respectively. ${ }^{13}$

Wide varieties of materials have been found as foreign body in upper gastrointestinal tract. In our study 15 different varieties of objects were retrieved. Materials retained in the upper $\mathrm{Gl}$ tract generally fall into two categories, namely, a food bolus impaction and a true foreign body. ${ }^{11,18}$ Classifications for foreign bodies, which define anatomic region and shape, are important for defining optimal therapy. ${ }^{10}$ Once foreign body ingestion is diagnosed, the gastroenterologist must decide whether intervention is necessary, how fast, and what will the best modality of intervention. The timing of endoscopic intervention depends on risks of possible complications like aspiration or perforation. However, no foreign object or food bolus impaction should be allowed to remain in the esophagus beyond 24 hours after presentation. ${ }^{19}$ Foreign bodies like sharp objects and disk batteries lodged in the esophagus require urgent endoscopic intervention to avoid perforation. Similarly, urgent intervention is also needed for impacted foreign bodies causing obstruction and excessive salivation which may lead to aspiration.

For retrieving foreign bodies various endoscopy accessory tools like grasping forceps, alligator forceps, rat tooth forceps, tripod forceps, polypectomy snares, Roth net, baskets, retrieval snare net, transparent cap-fitting device and overtube are used. In our study, commonly used accessory devices were rat tooth/ alligator foreign body forceps, snare loop, a net, tripod forceps, biopsy forceps and overtube. An overtube protects the airway and facilitates passage of the endoscope during removal of multiple objects or piecemeal removal of a food impaction. An overtube also protects the esophageal or gastroesophageal junction mucosa from laceration during retrieval of sharp objects. ${ }^{20}$ Foreign bodies and food impactions in the esophagus have the highest incidence of complications with the complication rate directly proportional to the dwell time in the esophagus. ${ }^{14} \mathrm{An}$ esophageal food bolus impaction often contains chewed meat lodged at one of the narrowed sites. Using a snare or snare basket, a food bolus can be retrieved in one piece or by piecemeal extraction or reduced in volume allowing it to pass spontaneously. The food may be successfully pushed into the stomach after it is cut into small pieces by a snare. If the object has passed into the stomach and is less than $2 \mathrm{~cm}$ in size, it will usually pass through the entire gastrointestinal tract without difficulty.

Button/small disk batteries are found in watches, hearing aids, calculators and other electronic devices may result in corrosive injury, necrosis and perforation of gastrointestinal tract. After radiographic documentation, batteries lodged in the esophagus or stomach should be emergently removed. Use of a retrieval snare net or a stone retrieval basket is most often successful. Surgical management is recommended if severe abdominal pain develops or if the battery fails to pass in 72 hours.

Common sharp pointed foreign bodies include bones, toothpicks, needles, safety pins, nails, dental appliances and medication blister packs. They should be removed, if possible, before they pass through the stomach, as these objects may perforate the intestine. Sharp objects within the esophagus should be urgently removed endoscopically. Surgical intervention is indicated if the patient develops symptoms of perforation or if the ingested sharp object fails to progress within 72 hours after ingestion. ${ }^{21}$ It can be removed by a snare net. For removal of sharp and pointed objects, use of an overtube or a retractable latex-rubber condom-type hood is recommended. Pointed objects should always be removed such that the pointed end is trailing as done in a safety pin or fish bone removal. These objects can also be retrieved using a polypectomy snare. Objects greater than $5 \mathrm{~cm}$ in length, such as pens, tooth brushes, spoons and cutlery usually lodge in the duodenal sweep and generally require endoscopic removal with a polypectomy snare. In the present study FB management was successful in $92.19 \%$ patients with flexible endoscopy and failed in $7.81 \%$ patients. High success rate is 
also noticed by Yao CC et al. ${ }^{13}$ who had a success rate $98.8 \%$.

Our study also has certain limitations. It is a hospital-based study so results obtained from this study can not be generalized. Furthermore, foreign body in upper gastrointestinal tract is also dependent upon the dietary habits of the population.

\section{CONCLUSION}

Foreign body ingestion is an important emergency clinical situation seen commonly in children and young adults with female predominance. Most common upper gastrointestinal foreign bodies are related to food bolus impaction with animal bone or meat. Retrosternal discomfort with dysphagia was the most common presentation. Lower esophagus is the most common site of impaction. Therapeutic endoscopy by an experienced, skilled endoscopist with suitable accessories is a reliable, safe and effective method in managing foreign body from upper gastrointestinal Tract. It has a very high success rate, low morbidity and no mortality. A variety of endoscopic techniques

\section{REFERENCES:}

1. Schwartz GF, Polsky HS. Ingested foreign bodies of the gastrointestinal tract. Am Surg. 1976 Apr;42(4):236-8. [PMID]

2. Vizcarrondo FJ, Brady PG, Nord HJ. Foreign bodies of the upper gastrointestinal tract. Gastrointest Endosc. 1983 Aug;29(3):208-10. [DOI]

3. Nandi P, Ong GB. Foreign body in the oesophagus: review of 2394 cases. Br J Surg. 1978 Jan;65(1):5-9. [DOI]

4. Webb WA. Management of foreign bodies of the upper gastrointestinal tract. Gastroenterology. 1988 Jan;94(1):204-16. [DOI]

5. Waltzman ML, Baskin M, Wypij D, Mooney D, Jones D, Fleisher G. A randomized clinical trial of the management of esophageal coins in children. Pediatrics 2005; 116: 614-619. [DOI]

6. Macpherson RI, Hill JG, Othersen HB, Tagge EP, Smith CD. Esophageal foreign bodies in children: diagnosis, treatment, and complications. AJR Am J Roentgenol 1996; 166: 919-924. [DOI]

7. Roura J, Morelló A, Comas J, Ferrán F, Colomé M, Traserra J. Esophageal foreign bodies in adults. ORL J Otorhinolaryngol Relat Spec 1990; 52: 5156. [DOI]

8. Matsubara M, Hirasaki S, Suzuki S. Gastric penetration by an ingested toothpick successfully managed with computed tomography and endoscopy. Intern Med. 2007;46: 971-974. [DOI]

9. Sugawa $\mathrm{C}$, Ono H. Taleb M, and Lucas CE., "Endoscopic management of foreign bodies in the upper gastrointestinal tract: a review,". World Journal of Gastrointestinal Endoscopy 2014;6(10): 475-481. [DOI]

10. Ginsberg GG. Management of ingested foreign objects and food bolus impactions. Gastrointest Endosc 1995; 41: 33-38. [DOI]

11. Conway WC, Sugawa C, Ono H, Lucas CE. Upper GI foreign body: an adult urban emergency hospital experience. Surg Endosc 2007; 21: 455-460. [DOI] and instruments are indicated for different situations.

\section{DISCLOSURE}

All authors have no disclosure of any financial involvement in any organization with a direct financial interest in the subject matter or materials discussed in the paper.

\section{CONFLICT OF INTERESTS}

The authors declare that there is no conflict of interests regarding the publication of this paper.

\section{ACKNOWLEDGEMENTS}

Authors are indebted to all our patients and staff of endoscopy unit of Universal College of Medical Sciences, Bhairahawa, Nepal who supported during the study. Authors are also thankful to Dr. Nagendra Chaudhary from Department of Pediatrics, UCMS for his technical support during the manuscript preparation.

12. Bini M. Gastrointestinal Foreign Bodies: Clinical Aspects and Endoscopic management. Journal of Gastroenterology and Hepatology Research 2015; 4(3): 1524-532. [DOI]

13. Yao CC, Wu IT, Lu LS, et al. Endoscopic management of foreign bodies in the upper gastrointestinal tract of adults. Biomed Res Int 2015 ;2015:658602. [DOI]

14. Telford JJ. Management of ingested foreign bodies. Can J Gastroentero 2005; 19: 599-601. [DOI]

15. Young CA, Menias CO, Bhalla S, Prasad SR. CT features of esophageal emergencies. Radiographics 2008; 28: 1541-1553. [DOI]

16. Nassar E, Yacoub R, Raad D, Hallman J, Novak J. Foreign Body Endoscopy Experience of a University Based Hospital. Gastroenterology Res. 2013;6(1):4-9. [DOI]

17. Anwar A, Hashmi MA, Khaliq S. Upper gastrointestinal tract foreign bodies in children: presentation and management. Pak Armed Forces Med J 2018; 68 (3): 634-38.

18. Ikenberry SO, Jue TL, Anderson MA, Appalaneni V, Banerjee S, Ben-Menachem T, Decker GA, Fanelli RD, Fisher LR, Fukami N, Harrison ME, Jain R, Khan KM, Krinsky ML, Maple JT, Sharaf R, Strohmeyer L, Dominitz JA. Management of ingested foreign bodies and food impactions. Gastrointest Endosc 2011; 73: 1085-1091. [DOI]

19. Loh KS, Tan LK, Smith JD, Yeoh KH, Dong F. Complications of foreign bodies in the esophagus. Otolaryngol Head Neck Surg 2000; 123: 613-616. [DOI]

20. Tierney WM, Adler DG, Conway JD, Diehl DL, Farraye FA, Kantsevoy SV, Kaul V, Kethu SR, Kwon RS, Mamula P, Pedrosa MC, Rodriguez SA. Overtube use in gastrointestinal endoscopy. Gastrointest Endosc 2009; 70: 828-834. [DOl]

21. Webb WA. Management of foreign bodies of the upper gastrointestinal tract: update. Gastrointest Endosc 1995; 41: 39-51. [DOl] 